\title{
PERANCANGAN DAN PENGEMBANGAN PRODUK PRIVATE ROOM SECURITY SYSTEM BERBASIS FINGERPRINT DENGAN PENGUKURAN KEPUASAN KONSUMEN MENGGUNAKAN QFD
}

\author{
Rif'an Afandy ${ }^{1)}$, Trismawati ${ }^{2)}$, Mustakim ${ }^{3)}$ \\ 1,2,3) Prodi Teknik Industri, Fakultas Teknik, Universitas Panca Marga \\ Email : rifanafandy1997@gmail.com
}

\begin{abstract}
Abstrak, Keamanan merupakan salah satu kebutuhan manusia berdasarkan pada kebutuhan fisiologis yang harus terpenuhi selama hidupnya, karena dengan terpenuhinya rasa aman setiap individu dapat berkarya dengan optimal dalam hidupnya. Keamanan merupakan bahasan yang luas, namun dalam hal ini kajian tentang keamanan dibatasi dalam lingkup keamanan rumah saja. Hasil penelitian ini adalah berupa produk sistem keamanan rumah, yaitu pengunci rumah berbasis fingerprint. Untuk sistem pengontrol menggunakan Mikrokontroller Arduino Atmega328 dan didukung oleh beberapa alat yang lain agar sistem keamanan bekerja dengan baik. Hadirnya produk pengunci pintu ini merupakan inovasi baru yang dapat meningkatkan keamanan dalam lingkup rumah dan dengan menggunakan perhitungan Quality Function Deployment (QFD) untuk mengetahui tingkat kepentingan dan kepuasan dari konsumen. Pengembangan produk ini sendiri difokuskan kepada beberapa fitur tambahan yang tidak dimiliki oleh produk serupa yang ada di pasaran.
\end{abstract}

Kata kunci : Sistem keamanan, Mikrokontroler, Fingerprint, QFD

\section{PENDAHULUAN}

Keamanan merupakan suatu kebutuhan manusia berdasarkan kebutuhan fisiologis yang harus terpenuhi selama hidupnya, karena dengan terpenuhinya rasa aman maka setiap orang dapat berkarya dengan optimal. Maraknya kasus pencurian di berbagai daerah sangat membuat masyarakat resah, sehingga menuntut masyarakat untuk selalu waspada setiap saat. Di Indonesia sendiri tingkat kriminalitas meningkat selama pandemi covid19. Data statistik kejahatan Polri pada minggu ke-19 dan ke-20 meningkat sebesar 7,04\%, Tingkat kejahatan yang terjadi pada pekan ke19 yaitu 3.481 kasus dan bertambah 245 pada minggu ke-20 menjadi 3.726 kasus kejahatan. Sistem keamanan yang lazim digunakan masih berupa kunci manual yang dapat diduplikat atau dibuka secara paksa, maka dalam pembuatan produk ini dipakailah sistem biometri yang berupa sidik jari. Karena keamanan pintu yang menggunakan sistem biometri sebagai pengamannya masih jarang ditemukan, baik pintu rumah, pintu kantor dll. Pada permasalahan penelitian ini, peneliti akan menggunakan metode Quality Function Deployment (QFD). Metode tersebut merupakan metode yang sesuai untuk melakukan pengembangan suatu produk.

Adapun hasil penelitian yang dilakukan sebagai perbandingan tidak terlepas dengan topik penelitian yaitu mengenai perancangan dan pengembangan produk pengaman pintu berbasis fingerprint. Berdasarkan hasil penelitian yang telah dilakukan oleh peneliti terdahulu, yaitu:

1. Juli Dian Purbani (2010) Pembuatan Mesin Identifikasi Sidik Jari Sebagai Kunci Pengaman Pintu.

2. Achmad Fatahilah (2019) Perancangan Dan Pengembangan Produk Lampu Rumah Berbasis Mikrokontroler Arduino.

3. Akbar Iskandar, Muhajirin, Lisah (2017) Sistem Keamanan Pintu Berbasis Arduino Mega.

\section{METODE}

\section{A. Metode Pengumpulan Data}

Dalam penelitian ini digunakan metodemetode yang sesuai dengan masalah tersebut, adapun metode yang digunakan adalah sebagai berikut:

1. Metode Observasi adalah salah satu metode untuk memperoleh data-data dengan mengamati secara langsung dan mencatat hal yang berhubungan dengan permasalahan secara sistematis

2. Studi literatur adalah metode yang berfungsi sebagai pedoman dan landasan teori data-data observasi dan tanya jawab, yaitu dengan cara studi 
perpustakaan dan buku-buku yang ada kaitannya dengan hal yang akan dibahas.

3. Metode Eksperimen Perancangan Security System pada Private Room akan dihasilkan setelah dilakukan serangkaian uji coba dan dilakukan percobaan terhadap alat tersebut.

\section{B. Metode Perancangan}

Langkah perancangan alat ini diawali dengan perancangan elektronik yang meliputi semua tahapan dari pembuatan produk yang berhubungan langsung dengan rangkaian, diantaranya adalah:

1. Membuat desain rangkaian atau menganalisis rangkaian.

2. Pembuatan koding atau menyusun kodekode program.

3. Pemasangan komponen yang telah dibuat dan pemasangan pada bagian pintu.

\section{Kerangka Penelitian}

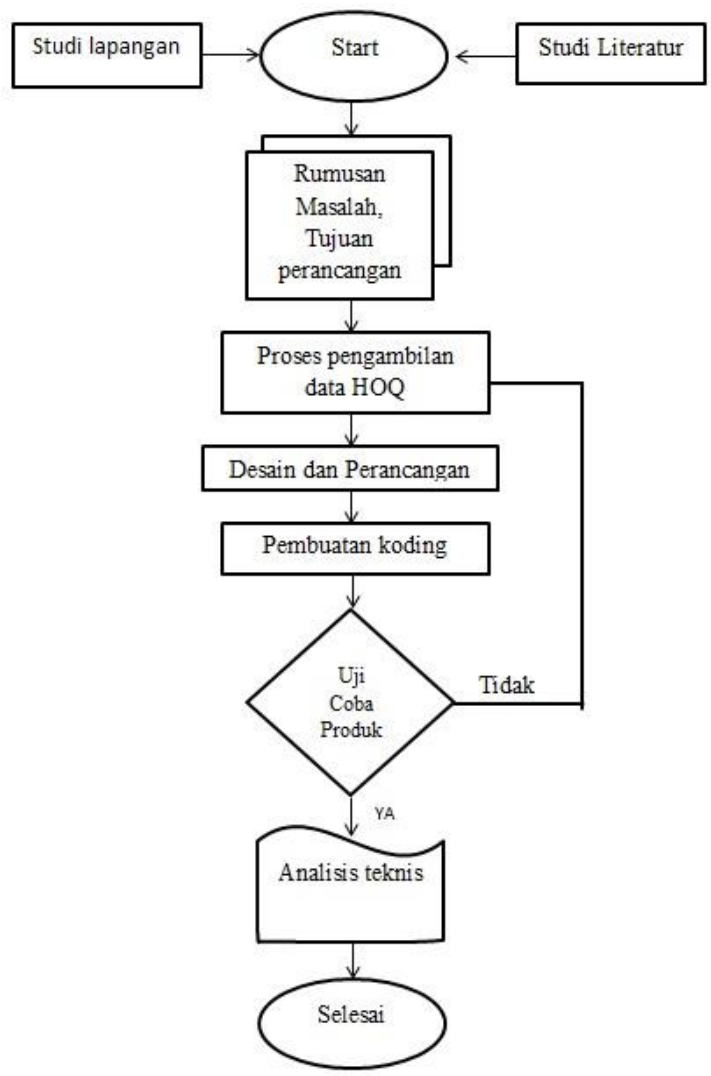

\section{HASIL DAN PEMBAHASAN Analisis data Quality Function Deployment (QFD)}

1. Voice of Customer (VOC)

Peneliti melakukan penyebaran kuesioner kepada 40 orang dengan sample yang sama, yaitu warga sekitar lokasi penelitian. Tujuan kegiatan survei ini, yaitu untuk mengetahui apakah hasil produk pengembangan pengunci pintu yang sudah dirancang sesuai dengan apa yang diharapkan dan bisa diterima atau tidak.

Atribut survei dan dilakukan penyebaran kuisioner, dimana kuesioner menggunakan skala linket 1-5. Adapun data yang diolah dari hasil kuesioner yang dilakukan terhadap hasil Produk Pengunci Pintu bisa dilihat pada tabel berikut:

Tabel 1. Voice of Customer

\begin{tabular}{|c|c|c|c|c|c|c|}
\hline \multirow{3}{*}{ No } & \multirow{3}{*}{ Atribut } & \multicolumn{5}{|c|}{ Tingkat Kepentingan (Banyaknya Responden) } \\
\hline & & $\begin{array}{l}\text { Tidak } \\
\text { Puas }\end{array}$ & $\begin{array}{c}\text { Kurang } \\
\text { Puas }\end{array}$ & Puas & $\begin{array}{c}\text { Cukup } \\
\text { Puas }\end{array}$ & $\begin{array}{c}\text { Sangat } \\
\text { Puas }\end{array}$ \\
\hline & & 1 & 2 & 3 & 4 & 5 \\
\hline 1 & Desain & 2 & 8 & 18 & 6 & 6 \\
\hline 2 & $\begin{array}{l}\text { Sistem } \\
\text { keaman } \\
\text { an }\end{array}$ & & & 14 & 16 & 10 \\
\hline 3 & Bahan & 5 & 6 & 9 & 20 & \\
\hline 4 & $\begin{array}{l}\text { Mudah } \\
\text { digunak } \\
\text { an }\end{array}$ & & 5 & 15 & 11 & 9 \\
\hline
\end{tabular}

2. Karakteristik Teknis (Technical Response)

Pada bagian ini, yaitu definisi secara teknis kepuasan konsumen yang berhubungan dengan hasil perancangan Produk Pengunci Pintu yang telah dilakukan. Karakteristik teknis yang dilakukan sesuai dengan kondisi produk hasil perancangan Produk Pengunci Pintu yang sudah peneliti rancang untuk kebutuhan customer. Atribut hasil perancangan Pengunci Pintu yang telah dilakukan bisa dilihat pada tabel di bawah ini:

Gambar 1. Kerangka penelitian 
Tabel 2. Atribut

\begin{tabular}{|c|l|l|}
\hline No & \multicolumn{1}{|c|}{ Atribut } & \multicolumn{1}{|c|}{ Karakteristik Teknis } \\
\hline 1 & Desain & Bentuk desain simpel \\
\hline 2 & $\begin{array}{l}\text { Sistem } \\
\text { keamanan }\end{array}$ & Akurasi keamanan tinggi \\
\hline 3 & Bahan & Bahan mudah didapat \\
\hline 4 & $\begin{array}{l}\text { Mudah } \\
\text { digunakan }\end{array}$ & $\begin{array}{l}\text { Menggunakan sidik jari } \\
\text { sebagai pengunci }\end{array}$ \\
\hline
\end{tabular}

3. Perhitungan tingkat kepuasan konsumen

Pengukuran tingkat kepuasan konsumen pada hasil produk adalah untuk mengukur bagaimana kepuasan konsumen tentang hasil produk yang telah dibuat oleh peneliti. Pengukuran kepuasan konsumen sangatlah penting untuk hasil produk yang sudah dirancang, dari hasil pengukuran inilah peneliti dapat mengetahui bagian-bagian mana yang akan dikembangkan kembali untuk diperbaiki. Untuk hasil perhitungan tingkat kepuasan konsumen dari atribut bisa dilihat pada tabel di bawah ini:

Tabel 3. Tingkat kepuasan konsumen

\begin{tabular}{|l|c|c|c|c|c|c|c|}
\hline \multirow{3}{*}{ Atribut } & \multicolumn{5}{|c|}{ Hasil Kuisioner } & \multirow{2}{*}{$\begin{array}{c}\text { Total } \\
\text { Score }\end{array}$} & $\begin{array}{c}\text { Tingkat } \\
\text { Kepuasa } \\
\text { n }\end{array}$ \\
\cline { 2 - 6 } & 1 & 2 & 3 & 4 & 5 & & \\
\hline Desain & 2 & 8 & 18 & 6 & 6 & 126 & 3.15 \\
\hline $\begin{array}{l}\text { Sistem } \\
\text { keamanan }\end{array}$ & & & 14 & 16 & 10 & 156 & 3.9 \\
\hline Bahan & 5 & 6 & 9 & 20 & & 124 & 3.1 \\
\hline $\begin{array}{l}\text { Mudah } \\
\text { digunakan }\end{array}$ & & 5 & 15 & 11 & 9 & 144 & 3.6 \\
\hline
\end{tabular}

4. Hubungan Respon Teknis terhadap VOC

Penentuan antara kebutuhan teknik dengan suara konsumen memerlukan pengalaman dan pengetahuan yang cukup mendalam tentang semua hal yang terkait dengan hasil pengembangan Produk Pengunci Pintu. Banyak hal yang tidak bisa dipastikan begitu saja, namun memerlukan beberapa kali pengujian untuk mengetahui penyebabnya.

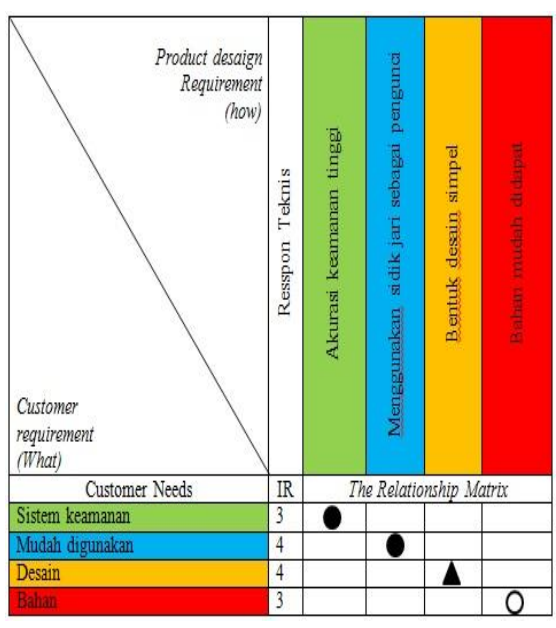

Gambar 2. Hubungan respon teknis terhadap VOC

5. Matriks Hubungan Korelasi Antar Respon Teknik

Beberapa performa respon teknis saling terhubung satu dengan yang lain. Mengembangkan salah satu karakteristik mutu dapat mendukung karakteristik yang berhubungan dengan hasil yang positif atau sebaliknya juga dapat mempengaruhi secara negatif.

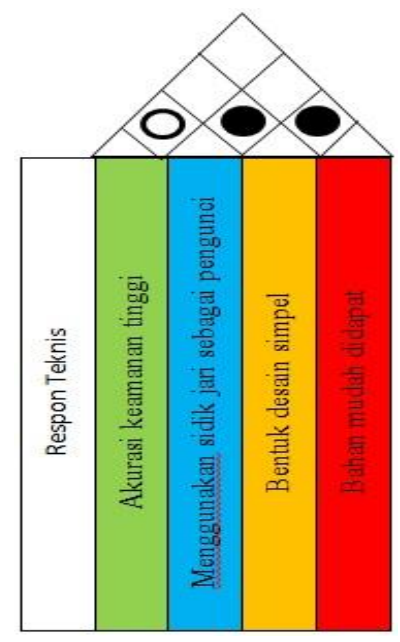

Gambar 3. Matriks korelasi respon teknis

6. Hasil House Of Quality (HOQ) Produk Pengunci Pintu 


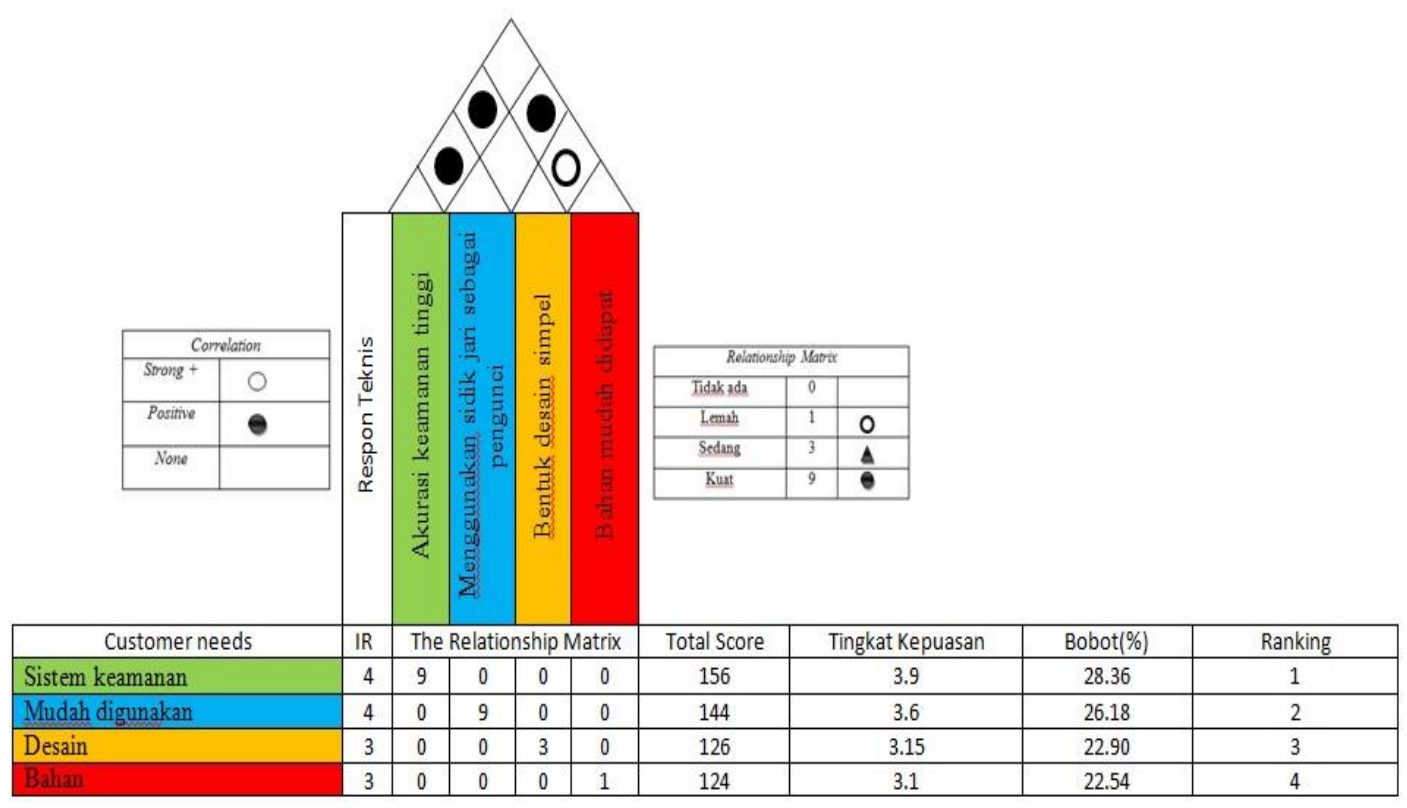

Gambar 4. House Of Quality

Berdasarkan dari hasil analisis matriks HOQ didapatkan bahwa hasil perhitungan bobot dan pe-ranking-an adalah sebagai berikut:

Tabel 4. Hasil kepuasan konsumen terhadap produk pengunci pintu

\begin{tabular}{|c|l|l|c|c|c|}
\hline No & Atribut & $\begin{array}{l}\text { Respon } \\
\text { Teknis }\end{array}$ & $\begin{array}{c}\text { Ranki } \\
\text { ng }\end{array}$ & $\begin{array}{c}\text { Tingkat } \\
\text { Kepuasan }\end{array}$ & $\begin{array}{c}\text { Bobot } \\
(\%)\end{array}$ \\
\hline 1 & $\begin{array}{l}\text { Sistem } \\
\text { keaman } \\
\text { an }\end{array}$ & $\begin{array}{l}\text { Akurasi } \\
\text { keamanan } \\
\text { tinggi }\end{array}$ & 1 & 3.9 & 28.36 \\
\hline 2 & $\begin{array}{l}\text { Mudah } \\
\text { diguna } \\
\text { kan }\end{array}$ & $\begin{array}{l}\text { Mengguna } \\
\text { kan sidik } \\
\text { jari } \\
\text { sebagai } \\
\text { pengunci }\end{array}$ & 2 & 3.6 & 26.18 \\
\hline 3 & Desain & $\begin{array}{l}\text { Bentuk } \\
\text { desain } \\
\text { simple }\end{array}$ & 3 & 3.15 & 22.90 \\
\hline Bahan & $\begin{array}{l}\text { Bahan } \\
\text { mudah } \\
\text { didapat }\end{array}$ & 4 & 3.1 & 22.54 \\
\hline
\end{tabular}

\section{Hasil Perancangan}

1. Perancangan Perangkat Lunak (Software)

Pembuatan diagram alir program sebagai acuan dalam proses pembuatan program. Adapun diagram alir sistem (flow chart) dalam perancangan ini dapat dilihat pada gambar di bawah ini:

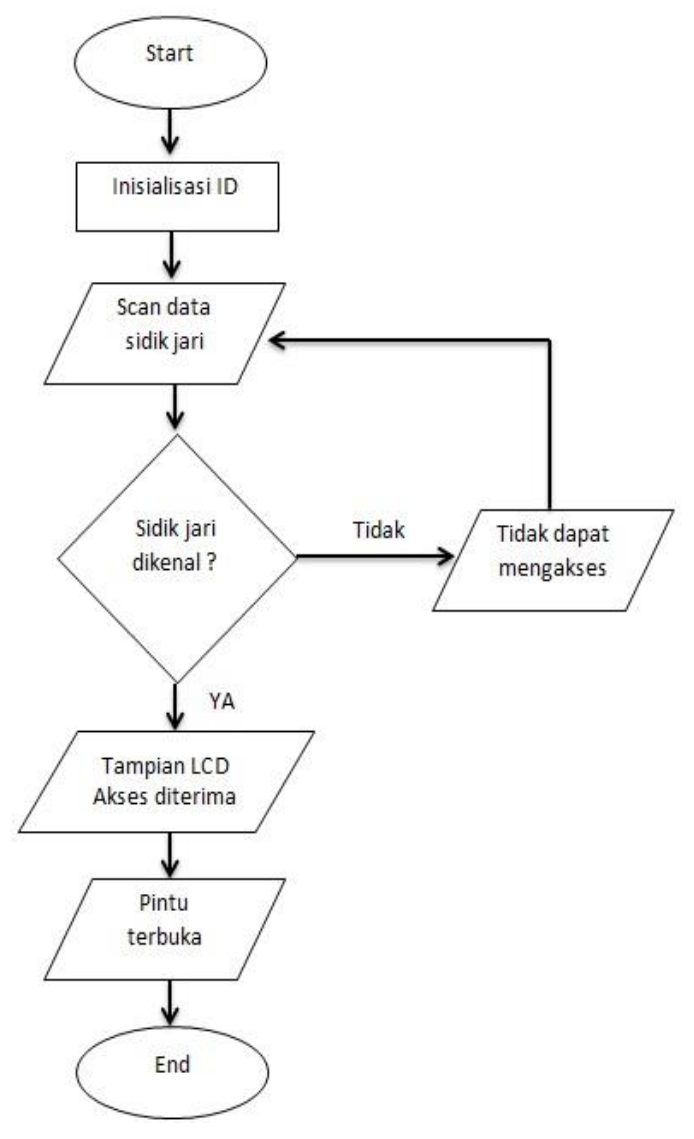

Gambar 5. Flowchart sistem

Pada tahapan ini, peneliti menggunakan software berupa aplikasi Arduino IDE untuk membuat kode program yang nantinya akan di-upload ke pengendalian utama yaitu board mikrokontroler ATmega328. 
Inputkan kode program arduino sesuai dengan type arduino yang akan digunakan. Pada kali ini, peneliti menggunakan Arduino Atmega328, dimana dalam penginputan kode program yang akan diproses. Tampilan kode program arduino IDE yang akan di-upload dapat dilihat pada gambar di bawah ini:

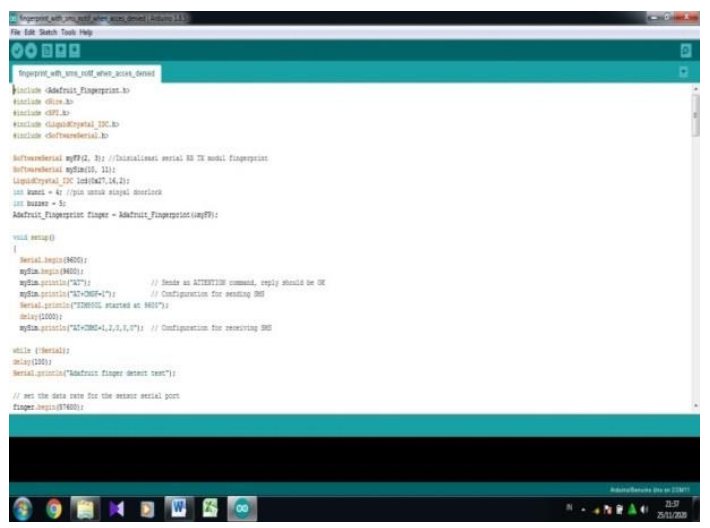

Gambar 6. Tampilan kode arduino

Pada tahap ini, peneliti menghubungkan perangkat Arduino ATmega328 dengan perangkat komputer menggunakan kabel USB. Di tampilan layar aplikasi arduino IDE terdapat tombol upload, dimana tombol tersebut berfungsi sebagai tombol perintah upload program IDE ke perangkat pengendalian utama, yaitu board arduino ATmega328.

2. Perancangan perangkat keras (Hardware)

Perancangan perangkat keras merupakan perancangan atau rangkaian dari suatu alat yang digunakan untuk membuat produk pengunci pintu dengan pengendalian berbasis mikrokontroler arduino ATmega328.

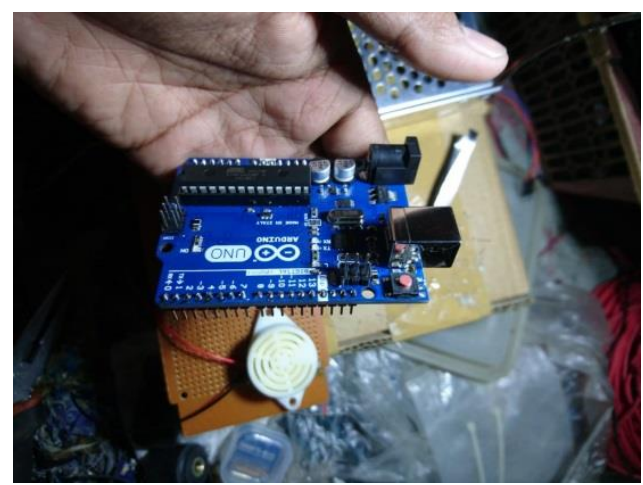

Gambar 7. Proses perakitan board arduino
ATmega328 ke PCB

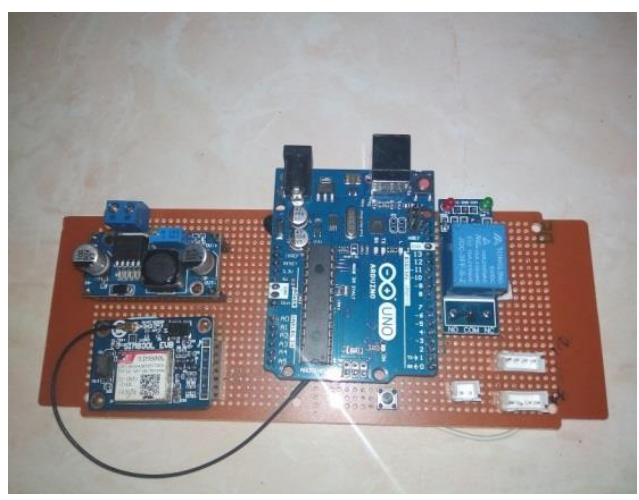

Gambar 8. Proses perakitan Relay ke PCB

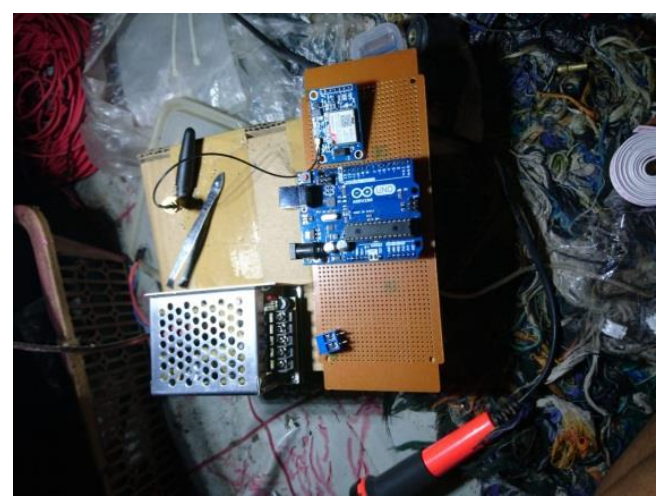

Gambar 9. Proses perakitan sim8001 ke board PCB

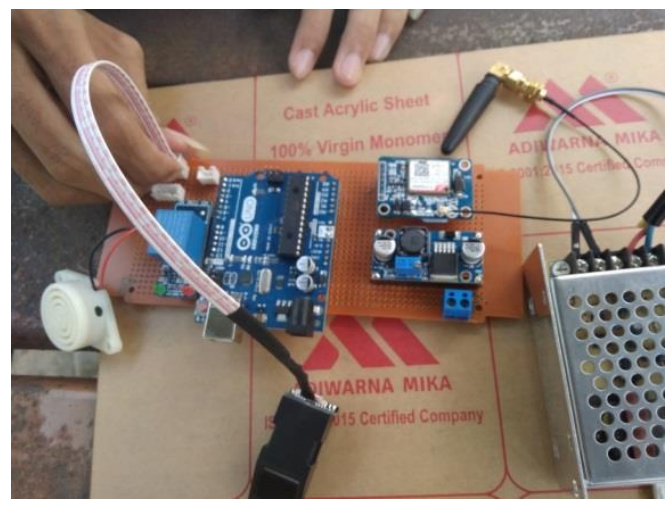

Gambar 10. Proses pemasangan fingerprint module ke board PCB 


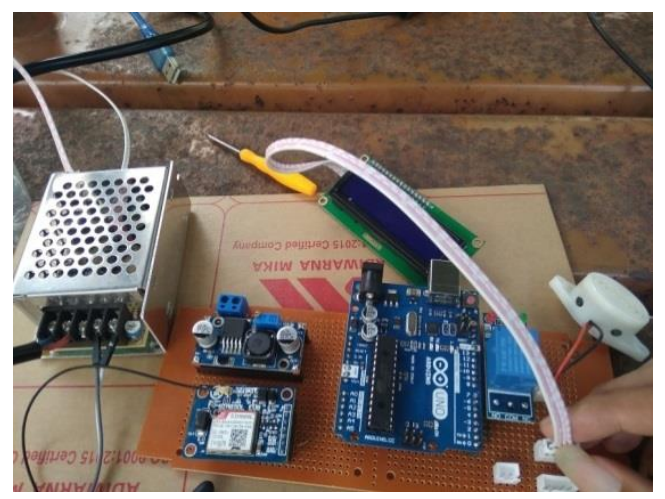

Gambar 11. Proses perakitan LCD 16x2 dengan board arduino

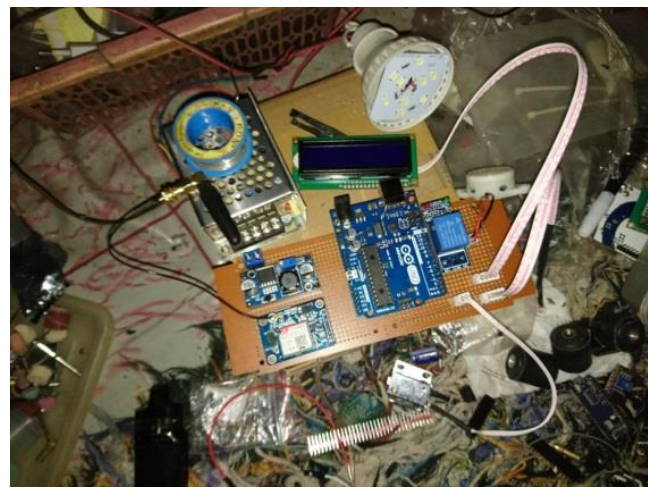

Gambar 12. Proses perakitan selenoid doorlock ke arduino

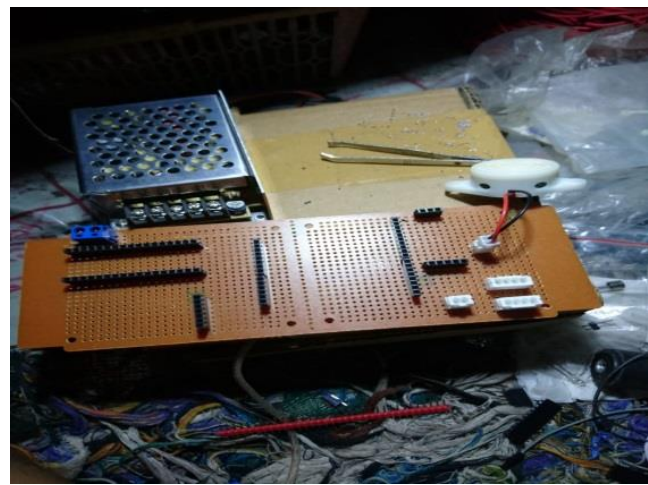

Gambar 13. Proses pemasangan buzzer

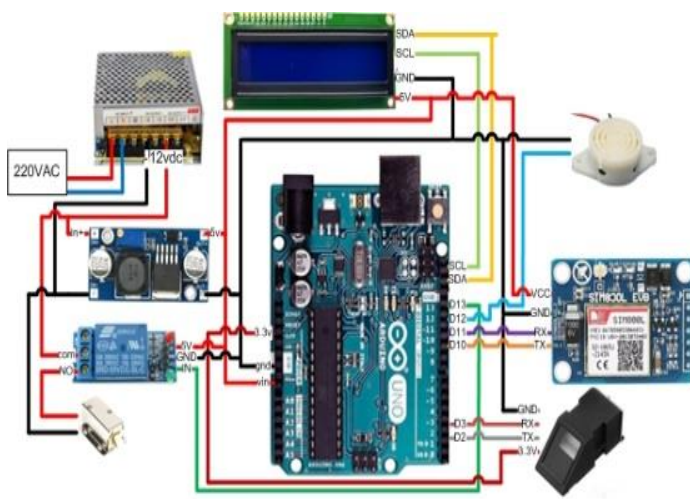

Gambar 14. Tampilan seluruh rangkaian sistem

3. Cara Kerja Produk

Perancangan proses kerja produk pengunci pintu diharapkan bisa menjadikan sistem pengaman pintu yang dibuat dapat berjalan dengan baik. Alur kerja produk yang dibuat sebagai garis besarnya saja untuk mempermudah dalam menjaga aset atau barang yang berada dalam private room. Sistem akan bekerja jika mikrokontroler ATMega328 telah mendapatkan supply tegangan dan arus sebesar 5 volt.

4. Proses Pendaftaran Sidik Jari

a. Buka aplikasi arduino IDE dan pastikan aplikasi siap merekam sidik jari atau ID yang akan dimasukan

b. Letakkan sidik jari yang akan direkam di fingerprint module

c. Setelah sidik jari terekam di fingerprint module, maka akan ada pemberitahuan image taken di layar dan remove fingerprint

d. Selanjutnya sidik jari ditempelkan lagi untuk melakukan verifikasi ID dan menyimpan sidik jari

5. Cara Kerja Alat Pengunci Pintu

Terdapat dua kondisi berbeda ketika mengoperasikan atau menjalankan produk fingerprint pembuka pintu 
- Kondisi pertama

1. Tempelkan jari yang sudah terdaftar sebelumnya di fingerprint module.

2. Tunggu beberapa saat sampai buzzer berbunyi bip pendek dan terdapat tulisan "terimakasih akses diterima" di layar monitor atau LCD.

3. Setelah itu selenoid akan terbuka dan kemudian terkunci kembali setelah 5 detik.

- Kondisi kedua (jika sidik jari tidak terdaftar)

1. Tempelkan sidik jari di fingerprint module.

2. Dalam beberapa saat jika sidik jari tidak terdaftar maka buzzer akan berbunyi bip panjang selama 3 detik.

3. Selanjutnya akan terdapat tulisan "maaf, akses ditolak" di monitor atau LCD.
4. Setelah itu board arduino akan mengirim sms "ID tidak dikenal mencoba masuk" ke nomor hp yang terdaftar di sistem koding melalui $\operatorname{sim} 8001$.

\section{Pengujian Sidik Jari}

Langkah pengujiannya adalah dengan menempatkan jari tangan pada area sensor fingerprint dengan catatan bahwa kondisi selenoid dalam keadaan terkunci, sehingga apabila sensor berhasil mengidentifikasi dan membaca sidik jari tersebut, maka sistem akan menghidupkan buzzer 1 kali dan solenoid aktif, kemudian pintu dapat dibuka, serta memberikan informasi di layar monitor atau LCD dan hitung mundur (count down) yang dibutuhkan oleh sistem didalam membaca sidik jari tersebut. Data tabel pengujian sidik jari dapat dilihat pada tabel di bawah ini:

Tabel 5. Hasil pengujian sidik jari

\begin{tabular}{|c|c|c|c|c|}
\hline No & Posisi tangan & Jari & Status & Waktu pembacaan \\
\hline 1 & \multirow{5}{*}{ Kanan } & Jempol & \multirow{5}{*}{ Terbaca } & \multirow{5}{*}{100 milidetik } \\
\hline 2 & & Telunjuk & & \\
\hline 3 & & Tengah & & \\
\hline 4 & & Manis & & \\
\hline 5 & & Kelingking & & \\
\hline 6 & \multirow{5}{*}{ Kiri } & Jempol & \multirow{5}{*}{ Terbaca } & \multirow{5}{*}{100 milidetik } \\
\hline 7 & & Telunjuk & & \\
\hline 8 & & Tengah & & \\
\hline 9 & & Manis & & \\
\hline 10 & & Kelingking & & \\
\hline & & & & \\
\hline
\end{tabular}

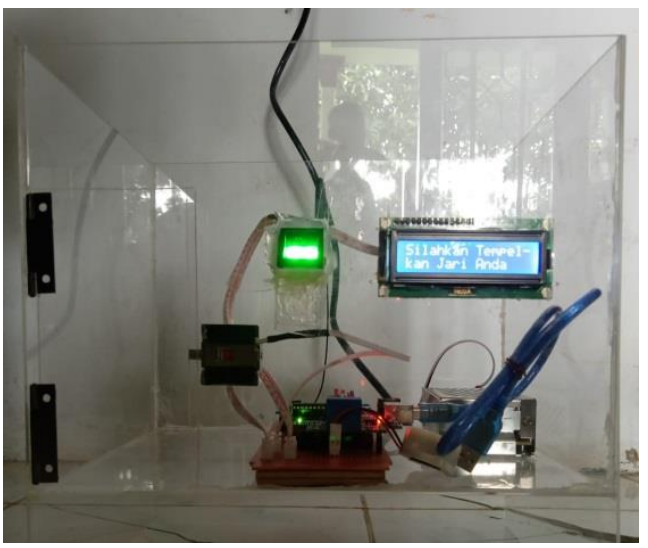

Gambar 15. Tampilan produk secara keseluruhan

\section{Analisis Teknis}

Analisis teknis pada produk pengunci pintu ini, meliputi sistem keamanan, mudah digunakan, desain dan bahan yang digunakan dalam pembuatan produk. Sistem keamanan pada produk pengunci pada produk ini, selain memiliki beberapa fitur yang tidak dimiliki oleh produk serupa yang ada di pasaran, juga memiliki sistem kontrol yang cukup bagus, karena menggunakan Arduino Atmega328 yang memiliki beberapa kelebihan jika dibandingkan dengan menggunakan server atau sofware 
yang membutuhkan banyak peralatan agar produk dapat bekerja dengan baik.

Selain memiliki sistem keamanan yang cukup baik, kemudahan dalam mengoperasikan produk juga menjadi salah satu faktor penentu, dimana pengguna dapat menggunakan produk dengan cukup baik, penggunaan sistem biometri yang diaplikasikan pada produk ini menjadi salah satu yang dapat mempermudah pengguna atau pemilik dalam menggunakan produk pengunci ini, karena pengguna cukup menempelkan jari yang sudah terdaftar.

Agar produk dapat bekerja dengan baik desain produk juga menentukan dimana posisi setiap elemen produk harus sesuai dengan kebutuhan agar tidak terjadi error pada produk ketika digunakan.

Pemilihan bahan juga menjadi salah satu faktor penentu apakah alat dapat bekerja dengan baik, jika pemilihan bahan tidak tepat maka dapat merusak rangkaian jika terjadi lonjakan daya atau penurunan daya secara tiba-tiba.

\section{KESIMPULAN DAN SARAN}

1. Pada tahapan membuat produk private room security system terdapat beberapa tahapan sehingga terbentuk desain alat yang diinginkan, sedangkan untuk perancangan ada tahapan untuk pembuatan kode program dan perakitan setiap elemen.

2. Analisis kajian teknis pada hasil produk pengembangan produk finger print pengunci pintu, yaitu sistem keamanan mudah digunakan, desain, dan bahan.

\section{DAFTAR PUSTAKA}

Achmad, Fatahilah. 2019. Perancangan Dan Pengembangan Produk Lampu Rumah Berbasis Mikrokontroler Arduino. Universitas Panca Marga, Probolinggo.

Akbar Iskandar, Muhajirin, Lisah. 2017. Sistem Keamanan Pintu Berbasis Arduino Mega. Teknik Informatika, STMIK AKBA.

Cohen, Lou. 1995. Quality Function Deploymant, Howto make QFD work for you. Addison Wesley Publishing Company. Massachussetts.
Eni, Yuliza. 2015. Alat Keamanan Pintu Brankas Berbasis Sensor Sidik Jari Dan Password Digital Dengan Menggunakan Mikrokontroler Atmega 16. Teknik Komputer, Fakultas Ilmu Komputer, Universitas Dehasen, Bengkulu.

Haris Isyanto, Husnibes Muchtar, Jefri Burhan. 2016. Perancangan Security System Kendaraan Menggunakan Fingerprint. Teknik Elektro, Fakultas Teknik, Universitas Muhammadiyah, Jakarta.

Ir. Rudy Wawolumaja, M.Sc. Sistem Pengaturan Otomatis (Level 2 sistem otomasi). Jurusan Teknik Industri, Fakultas Teknik, Universitas Kristen Maranatha.

Juli, Dian Purbani. 2010. Pembuatan Mesin Identifikasi Sidik Jari Sebagai Kunci Pengaman Pintu. Laporan penelitian. Universitas Sebelas Maret, Surakarta.

Salita, Ulitia Prini dan Handoko, Rusiana Iskandar. 2018. Desain dan Implementasi Sistem Absensi Mahasiswa Menggunakan Fingerprint Berbasis Mikrokontroler. Teknik Elektro, Universitas Jenderal Achmad Yani.

Sandri, Titik Wulandari, Ernawati, Endina Putri Purwandari. Aplikasi Biometrika Pengenalan Citra Sidik Jari Dengan Metode Minutiae Dan Artificial Neural Network Backpropagation. Program Studi Teknik Infomatika, Fakultas Teknik, Universitas Bengkulu.

Sandro, Lumban Tobing. Rancang Bangun Pengaman Pintu Menggunakan Sidik Jari (Fingerprint) Dan Smartphone Android Berbasis Mikrokontroler Atmega8. Program Studi Teknik Elektro, Jurusan Teknik Elektro, Fakultas Teknik, Universitas Tanjungpura, Pontianak.

Syahwil, Muhammad. 2013. Panduan Mudah Simulasi Dan Praktek Mikrokontroler Arduino. Andi.

Zainal Arifin, Dominicus Danardono Dwi Prija Tjahjana, Rendy Adhi Rachmanto, Suyitno, Singgih Dwi Prasetyo, Trismawati. Redesign Mata Bor Tanah untuk Pembuatan Lubang Biopori di Desa Puron, Kecamatan Bulu, Kabupaten Sukoharjo. Program Studi Teknik Mesin, Fakultas Teknik, Universitas Sebelas Maret, Surakarta. 